Check for updates

Cite this: RSC Adv., 2019, 9, 32699

Received 5th July 2019

Accepted 21st September 2019

DOI: $10.1039 / c 9 r a 05114 \mathrm{~g}$

rsc.li/rsc-advances

\section{Enhanced UHPLC-MS/MS determination of a therapeutic heptapeptide mimic for inflammatory-related diseases in rat plasma: application to a pharmacokinetic study}

\begin{abstract}
Liang $\mathrm{Li}^{\text {abc }}$ Shumei Ma, $\dagger^{\mathrm{d}}$ Yan Qin ${ }^{\mathrm{abc}}$ and Li Liu (D) *abc
The seven amino acid peptide, GQTYTSG (named as SP), a peptide mimic derived from hypervariable region 1 (HVR1) of the hepatitis C virus (HCV) has presented remarkable anti-inflammatory activities in previous experiments, indicating that it could be a novel therapeutic peptide candidate for different inflammationrelated diseases, such as HCV infection and asthma. A heptapeptide mimic discovery study highlighted the need for the development of quantitative bioanalytical assays for measuring the levels of SP. Herein, a reliable and sensitive ultrahigh-performance liquid chromatography (UHPLC) with tandem mass spectrometry (MS/MS) assay was established and validated for the determination of SP in rat plasma. C11, with two amino acid substitutions compared to SP (Glycine 1 and Glycine 7) and a disulfide, acted as an internal standard (IS). SP and C-11 were isolated from acidified plasma using protein precipitation and the extracts were analyzed by reversed-phase UHPLC-MS/MS detection. We used an SHIM-PACK GISS C18 $(2.1 \times 100 \mathrm{~mm}, 1.9 \mu \mathrm{m})$ column with water containing $0.2 \%$ acetic acid as the aqueous mobile phase and methanol as the organic mobile phase with a $0.3 \mathrm{~mL} \mathrm{~min}^{-1}$ flow rate. We used an AB SCIEX TripleQuadTM 5500 mass spectrometer equipped with a Turbolon Spray interface and operated it in positive-ion mode. Multiple reaction monitoring (MRM) was used for the quantification of the precursor to the product ion at $\mathrm{m} / \mathrm{z} 713.3 \rightarrow 432.2$ for SP and $\mathrm{m} / \mathrm{z} 803.2 \rightarrow 539.1$ for IS. The method was fully validated according to the US Food and Drug Administration (FDA) guideline (2018), and provided satisfactory accuracy, precision, and reproducibility for the quantification of SP in rat plasma. Excellent linearity was achieved ( $r>0.9977)$ over a linear dynamic range of $0.1-200 \mathrm{ng} \mathrm{mL}^{-1}$ with a lower limit of quantification (LLOQ) of $0.1 \mathrm{ng} \mathrm{mL} \mathrm{m}^{-1}$. The validated assay was applied to gain the pharmacokinetic (PK) parameters and the concentration-time profile for SP after subcutaneous administration in rats.
\end{abstract}

\section{Introduction}

Inflammation is a kind of defensive response of the body to exterior irritation, such as infection and damage, which might bring about negative changes to the involved tissues. ${ }^{1}$ Sometimes, it indicates a starting point of certain chronic diseases, such as tumours, skin disorders, arthritis, cardiovascular syndrome and asthma diseases. ${ }^{2}$ The inflammatory reaction includes the energizing of various biological mechanisms, such

\footnotetext{
${ }^{a}$ Center for Pharmacological Evaluation and Research, Shanghai Institute of Pharmaceutical Industry, China State Institute of Pharmaceutical Industry, Shanghai 200437, PR China. E-mail: liulisipi@foxmail.com; Tel: +8621-65043855

${ }^{b}$ State Key Laboratory of New Drug and Pharmaceutical Process, Shanghai 201203, PR China

${ }^{\circ}$ Shanghai Professional and Technical Service Center for Biological Material DrugAbility Evaluation, Shanghai 200437, PR China

${ }^{d}$ Department of Pharmacology, School of Pharmacy, Fudan University, Shanghai 201203, PR China

$\dagger$ Shumei Ma contributed equally to this work.
}

as the excretion and production of some pro-inflammatory mediators, such as growth factors, interleukins, cytokines and chemokines. ${ }^{3}$ However, this kind of inflammatory response is required to maintain homeostasis in injured biological compartments, and a change of regulation is involved with different inflammation-related diseases. ${ }^{4,5}$ The treatment of inflammation-related diseases usually depends heavily on conventional small molecule agents, which can potentially result in some unexpected side effects. ${ }^{6}$ Based on the low toxicity, high selectivity, high potency and broad range of targets, peptidebased therapies are being developed as an alternative treatment for different inflammatory disorders over the years.

A variety of bioactive peptides can be found in living organisms and nature is a key source of biologically active peptides. ${ }^{8}$ However, beyond the traditional focus on endogenous peptides, peptide drug discovery has turned into a broader range of entities developed from extra natural origins or from chemical libraries or from recombinant libraries. ${ }^{9,10}$ The bioinformatic approach, empirical approach and integrated approach are the three 
dominating means for seeking biologically active peptides according to present studies. ${ }^{11}$ Besides, there are other studies demonstrating the peptide display technology for exploring significant bioactive peptides. ${ }^{\mathbf{1 2}}$ Peptides discovered by these approaches have become the foundation for the development of therapeutic molecule entities.

Hepatitis $\mathrm{C}$ virus (HCV) is a type of ribonucleic acid virus that is responsible for most chronic and acute viral hepatitis, cirrhosis and hepatic carcinomas. ${ }^{13}$ The high-frequency mutation of the HCV gene during replication allows it to smoothly escape from an immune attack. ${ }^{14}$ The high rate of mutation happens cumulatively in a certain restricted region known as the hyper-variable region 1 (HVR1). ${ }^{15}$ HVR1, approximately a 28 amino acid long segment of the envelope protein E2, plays a key role in eliciting immune evasion. ${ }^{\mathbf{1 6}}$ Under our co-workers' research into HVR1, ${ }^{17}$ a battery of peptide mimics derived from HVR1 were discovered and verified for their anti-inflammatory properties in vitro and in vivo. One of these peptide mimics, the heptapeptide GQTYTSG (named SP, Fig. 1), was recognized for its stronger ability to produce a favourable cytokine profile, which could contribute to the anti-inflammatory and anti-virus immune response. ${ }^{18}$ The results showed that SP could decrease the serum levels of alkaline phosphatase, aminotransferases and bilirubin, and is beneficial to improve the histopathological evidence of a porcine serum-induced rat chronic liver injury. ${ }^{\mathbf{1 9}}$ Furthermore, SP could notably suppress immunoglobulin E production from B cell, control T-helper 9 cells development in the lung and reduce the airway reactivity in a murine asthma model. ${ }^{20}$ The World Intellectual Property Organization has granted a patent for SP (No. PCT/CN2006/001176).

The accurate determination of SP in a biological matrix is pivotal for evaluating its pharmacokinetics and toxicokinetics in a preclinical study. Hitherto that date, no bioanalytical assay or relevant pharmacokinetic (PK) research has been reported for SP. Allowing for the rapid decomposition of straight-chain SP in blood samples due to enzymatic degradation with a half-life of less than $10 \mathrm{~min}\left(25^{\circ} \mathrm{C}\right.$, in vitro $)$, the general sample preparation requires processing immediately after being drawn from rats. ${ }^{21}$ However, this method is not suitable as it is time-consuming and requires intensive manpower effort, which makes it especially challenging when a lab is faced with a large number of samples. Hence, it is crucial to figure out how to stabilize SP in blood samples during sampling while ensuring reliable and actual analytical data.

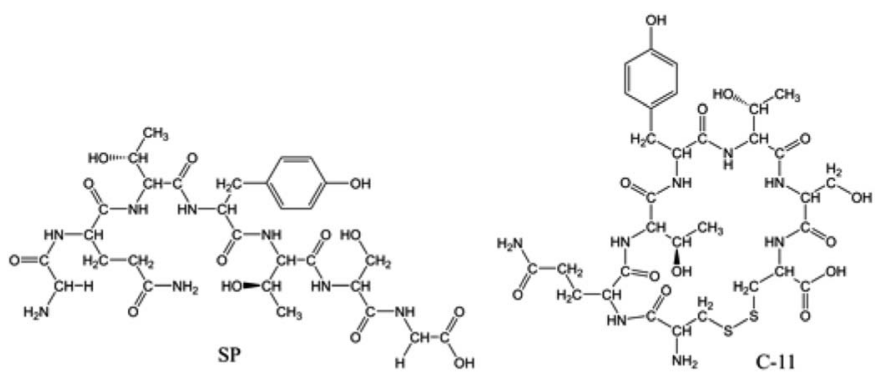

Fig. 1 Chemical structures of SP and C-11 (IS).
Table 1 Gradation of the mobile phase elution

\begin{tabular}{llll}
\hline Time $(\mathrm{min})$ & Flow rate $\left(\mathrm{mL} \mathrm{min}^{-1}\right)$ & $\mathrm{A} \%$ & $\mathrm{~B} \%$ \\
\hline Initial & 0.300 & 98 & 2 \\
0.50 & 0.300 & 98 & 2 \\
1.50 & 0.300 & 81 & 19 \\
3.00 & 0.300 & 81 & 19 \\
3.50 & 0.300 & 20 & 80 \\
4.50 & 0.300 & 20 & 80 \\
4.60 & 0.300 & 98 & 2 \\
6.00 & 0.300 & 98 & 2 \\
\end{tabular}

In this context, we established and fully validated a reliable and sensitive ultrahigh-performance liquid chromatography with the tandem mass spectrometry (UHPLC-MS/MS) assay to quantify SP in rat plasma. C-11, a stable cyclic peptide derived from SP, served as an internal standard (IS). The assay was then performed to evaluate the PK properties of SP. The results were intended to provide a key reference and an essential complement for an assay to support the clinical study of SP.

\section{Experimental}

\section{Chemicals and reagents}

SP (99.4\% purity) was provided by Rui Yunhai Bio-Technology Co., Ltd (Beijing, China). C-11 (purity $\geq 99 \%$ ) was synthesized by Naval Medical University (Shanghai, China). The chemical structures are presented in Fig. 1. The molecular weight of SP was 712.30 Da, and that of C-11 was 802.26 Da.

Methanol (HPLC grade) was purchased from Merck Company (Darmstadt, Germany). LC/MS-grade acetic acid was purchased from Fisher Scientific (Loughborough, UK). cOmplete $^{\mathrm{TM}}$ protease inhibitor cocktail tablets were purchased from Roche (Mannheim, Germany). Pepstatin A (purity $\geq 98.0 \%$ ) and aprotinin (3-7 TIU per mg protein) were purchased from SigmaAldrich (Missouri, USA). Biotech grade 4-(2-aminoethyl) benzenesulfonyl fluoride hydrochloride (AEBSF, purity $\geq 97.0 \%$ ) was purchased from Fisher Scientific (Loughborough, UK). Analytical reagent sulphuric acid $\left(\mathrm{H}_{2} \mathrm{SO}_{4}, 95-98 \%\right)$ was purchased from Sinopharm Chemical Reagent Co., Ltd (Shanghai, China), and guaranteed reagent perchloric acid $\left(\mathrm{HClO}_{4}, 70.0-72.0 \%\right)$ was purchased from Macklin Biochemical Co., Ltd (Shanghai, China). HPLC-grade water was produced in-house by a Milli-Q purifying system (Bedford, USA). Blank rat blood (EDTA-K $\mathrm{K}_{2}$ or heparin sodium as the anticoagulant) containing $0.3 \%$ perchloric acid (v/v), obtained from the Centre for Pharmacological Evaluation and Research of Shanghai Institute of Pharmaceutical Industry (SIPI), was centrifuged at $1000 \times g$ for $15 \mathrm{~min}$ to gain the acidified rat plasma, and was then stored below $-70{ }^{\circ} \mathrm{C}$ until analysis.

\section{UHPLC-MS/MS analysis}

The UHPLC-MS/MS system was composed of an AB SCIEX ExionLC $^{\mathrm{TM}}$ AD system coupled to an AB SCIEX TripleQuad ${ }^{\mathrm{TM}}$ 5500 (Applied Biosystems, Foster City, CA, USA) equipped with 




Fig. 2 Product ion mass spectrum of SP (a) and IS (b). Illustration: the proposed fragmentation pathway.

an electrospray ionization (ESI) source. Data processing was performed using the MultiQuant ${ }^{\mathrm{TM}}$ software (Version 3.0.3, $\mathrm{AB}$ SCIEX).

The separation was performed on a SHIM-PACK GISS C18, $1.9 \mu \mathrm{m}, 2.1 \times 100 \mathrm{~mm}$ column (Shimadzu Corporation, Kyoto, Japan) coupled with a SHIM-PACK GISS-HP (G), $1.9 \mu \mathrm{m}, 2.1 \times$ $10 \mathrm{~mm}$ pre-column (Shimadzu Corporation, Kyoto, Japan) maintained at $50{ }^{\circ} \mathrm{C}$. The mobile phase consisted of methanol (mobile phase B) and water containing $0.2 \%$ acetic acid (v/v) (mobile phase A). The chromatographic analysis was performed with gradient elution, and the gradation of the elution is shown in Table 1. The temperature of the auto-sampler was set at $10^{\circ} \mathrm{C}$. The injection volume was $10 \mu \mathrm{L}$, and the total run time was $6.0 \mathrm{~min}$.

The mass spectrometry was performed in the positive ionization, multiple reaction monitoring (MRM) mode. The ionization parameters were optimized as follows: curtain gas (CUR), 35 psi; collision gas (CAD), 8 psi; gas1 (GS1), 60 psi; gas2 (GS2), $50 \mathrm{psi}$; ionization voltage, $5500 \mathrm{~V}$; source temperature, $550{ }^{\circ} \mathrm{C}$. Nitrogen was used as the CUR, CAD and nebulizing gas. The precursor ion (Q1) and product ion (Q3) quadrupoles were set at unit resolution. The dwell time was $150 \mathrm{~ms}$ for SP and C-11. The MRM transitions for SP and C-11 were at $m / z 713.3 \rightarrow 432.2$ and $803.2 \rightarrow 539.1$, respectively. Also, the fragmentation parameters, including the de-clustering potential, collision energy, collision cell exit potential and entrance potential, were $120 \mathrm{~V}$, $36.0 \mathrm{~V}, 16.7 \mathrm{~V}$ and $10 \mathrm{~V}$ for SP, and $150 \mathrm{~V}, 44.7 \mathrm{~V}, 9.7 \mathrm{~V}$ and $10 \mathrm{~V}$ for IS.

\section{Preparation of calibration samples and quality control samples}

The reference standard of SP was accurately prepared in water to gain separate stock solutions $\left(1 \mathrm{mg} \mathrm{mL}^{-1}\right)$ for the calibration standards and for quality control (QC) of the samples. Standard material as the IS was accurately weighed and dissolved in water-methanol $(50: 50, \mathrm{v} / \mathrm{v})$ at $1 \mathrm{mg} \mathrm{mL}^{-1}$ as the stock solution. The working solutions of SP $(1,5,25,100,500,1000$ and $2000 \mathrm{ng} \mathrm{mL}{ }^{-1}$ ) were gained by diluting the stock solution with water containing $0.2 \%$ acetic acid $(\mathrm{v} / \mathrm{v})$. The working solutions of QC samples (2.5, 50 and $\left.1500 \mathrm{ng} \mathrm{mL}^{-1}\right)$ were prepared as above. The working solution for IS $\left(500 \mathrm{ng} \mathrm{mL}^{-1}\right.$ ) was freshly prepared when necessary by diluting the stock solution with water containing $0.2 \%$ acetic acid (v/v). All the working solutions were kept at $4{ }^{\circ} \mathrm{C}$, and the aliquots of stock solutions after preparation were stored below $-70{ }^{\circ} \mathrm{C}$ prior to further use.

Seven non-zero calibration standards were freshly prepared on each day of analysis at the following concentrations: $0.1,0.5$, $2.5,10,50,100$ and $200 \mathrm{ng} \mathrm{mL} \mathrm{m}^{-1}$ by adding $5 \mu \mathrm{L}$ of the working solution of SP to a $45 \mu \mathrm{L}$ aliquot of blank acidified plasma. QC
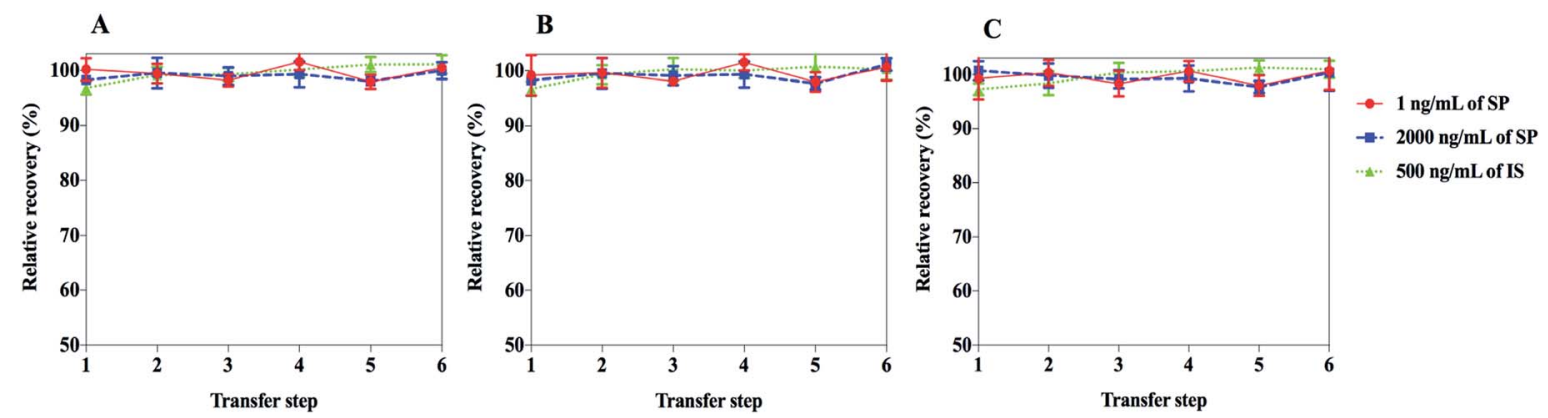

Fig. 3 Relative recovery of SP and IS after six transfer steps in different vessels $(n=3)$. SP was dissolved in the vessels indicated: (a) ordinary polypropylene tubes; (b) Eppendorf protein LoBind tubes; (c) glass tubes. After every 30 min storage at $25^{\circ} \mathrm{C}, 300 \mu \mathrm{L}$ was transferred from one vessel to the next for UHPLC-MS/MS analysis. 
samples were obtained in a similar way at low, medium and high concentrations $\left(0.25,5\right.$ and $\left.150 \mathrm{ng} \mathrm{mL} \mathrm{m}^{-1}\right)$.

\section{Estimation of adsorption}

To estimate the loss of SP and IS during the solution preparation, the extent of adsorption was measured. Adsorption was investigated at low and high concentrations (1 and $2000 \mathrm{ng}$ $\mathrm{mL}^{-1}$ ) of SP and at $500 \mathrm{ng} \mathrm{mL}^{-1}$ of IS. Six consecutive steps, transferring a portion of the working solutions from a ordinary polypropylene tube or Eppendorf Protein LoBind tube or glass tube to another, followed by UHPLC-MS/MS analysis, were followed to perform the adsorption test. Adsorption was evaluated by relative recovery, defined by comparing the peak area before and after transfer.

\section{Working solutions and stock solutions stability}

The stability of SP and IS in the working solutions under different conditions was inspected. The test concentrations were $2000 \mathrm{ng} \mathrm{mL} \mathrm{m}^{-1}$ for SP and $500 \mathrm{ng} \mathrm{mL} \mathrm{m}^{-1}$ for IS. Aliquots $(500$ $\mu \mathrm{L})$ of SP or IS working solution were set at ambient temperature $\left(25^{\circ} \mathrm{C}\right)$ and in an ice-water bath $\left(0{ }^{\circ} \mathrm{C}\right)$ for $6 \mathrm{~h}$, respectively. The loss of SP and IS was determined by comparing the peak area of the samples before and after incubation. Other aliquots $(500 \mu \mathrm{L})$ of SP or IS working solution were stored in an ice chamber $\left(4{ }^{\circ} \mathrm{C}\right)$ for 30 days. The long-term stability of the working solutions was evaluated by comparing the peak areas of the freshly prepared solutions and original solutions.

The stability of SP and IS in the stock solutions was also inspected. Aliquots ( $1 \mathrm{~mL}$ ) of SP or IS stock solution were stored in a freezer $\left(-70{ }^{\circ} \mathrm{C}\right)$ for 90 days. The loss of SP and IS was checked by comparing the peak areas of the freshly prepared solutions and original solutions. The stock solutions stability was assessed by HPLC with a diode array detector $(\lambda=224 \mathrm{~nm})$.

\section{Precipitant selection}

One of the most common and convenient sample processing methods is precipitation with organic solvents to remove plasma proteins, and for this, a selection of organic solvents was investigated herein. Medium concentration acidified



different volumes of acetonitrile or methanol with $0.2 \%$ acetic acid (v/v). Also, the samples were centrifuged for $10 \mathrm{~min}$ at $1000 \times g$ at ambient temperature. The supernatant was then transferred into a vial containing low-volume inserts for the UHPLC-MS/MS analysis. The extraction efficiency was examined by comparing the recovery of SP in samples precipitated with different volumes of different organic solvents.

\section{Sample processing}

Here, a $5 \mu \mathrm{L}$ working solution of IS (except for double blanks) was added into a volume of $50 \mu \mathrm{L}$ of each sample before being extracted by triple volumes $(150 \mu \mathrm{L})$ of cooled methanol containing $0.2 \%$ acetic acid $(\mathrm{v} / \mathrm{v})$. After shaking for $10 \mathrm{~min}$ on a horizontal shaker at 160 strokes per min, the samples were centrifuged for $10 \mathrm{~min}$ at $1000 \times g$ at ambient temperature. Then, $150 \mu \mathrm{L}$ of the supernatant was transferred into a tube and evaporated to dry under a nitrogen stream at $40{ }^{\circ} \mathrm{C}$. The residue was re-dissolved into $80 \mu \mathrm{L}$ of methanol : water : acetic acid $(2: 98: 0.2, \mathrm{v}: \mathrm{v}: \mathrm{v})$ by thoroughly mixing for $30 \mathrm{~s}$. The mixture was then centrifuged for $10 \mathrm{~min}$ at $1000 \times \mathrm{g}$ at room temperature. The supernatant was directly collected into a vial containing low-volume inserts for UHPLC-MS/MS analysis.

\section{Stabilization tactics for biological samples}

During method development, a couple of factors affecting the stabilization of SP in biological samples were probed, including anticoagulant, enzyme inhibitors and acidified samples. High concentration blood samples $\left(150 \mathrm{ng} \mathrm{mL}{ }^{-1}\right)$ were prepared and employed to evaluate the different factors. The sampleprocessing procedure was the same as in the previous section.

Anticoagulants. Samples using different anticoagulants (EDTA-K $\mathrm{K}_{2}$ and heparin sodium) were incubated at ambient temperature $\left(25^{\circ} \mathrm{C}\right)$ and in an ice-water bath $\left(0^{\circ} \mathrm{C}\right)$, respectively. The samples before incubation and at 2, 5, 10, 20, 30, $60 \mathrm{~min}$ after incubation were collected to measure the levels of SP. Then, the half-lives were calculated.

Protease inhibitors. To investigate the influence of protease inhibitors, including pepstatin A, aprotinin, cOmplete ${ }^{\mathrm{TM}}$ protease inhibitor cocktail tablets and AEBSF, the samples were incubated at ambient temperature $\left(25{ }^{\circ} \mathrm{C}\right)$. The samples containing different inhibitors before incubation and at the same

Table 2 Stability of the SP and IS in the stock solutions and working solutions

\begin{tabular}{|c|c|c|c|c|c|}
\hline Solution-type & $\begin{array}{l}\text { Compound } \\
\text { (concentration) }\end{array}$ & $\begin{array}{l}\text { Storage } \\
\text { condition }\end{array}$ & $\begin{array}{l}\text { Peak area of the fresh solution }{ }^{a} \\
(\text { mean } \pm \mathrm{SD}, n=5)\end{array}$ & $\begin{array}{l}\text { Peak area of the original solution }{ }^{a} \\
(\text { mean } \pm \mathrm{SD}, n=5)\end{array}$ & $\begin{array}{l}\text { Percentage of } \\
\text { initial level }(\%)\end{array}$ \\
\hline \multirow[t]{6}{*}{ Working solution } & $\mathrm{SP}\left(2000 \mathrm{ng} \mathrm{mL}^{-1}\right)$ & $25^{\circ} \mathrm{C}$ for 6 hours & $29855000 \pm 964421$ & $29942000 \pm 101825$ & 100.3 \\
\hline & & $0{ }^{\circ} \mathrm{C}$ for 6 hours & $30184000 \pm 227618$ & $29916000 \pm 382537$ & 99.1 \\
\hline & & $4{ }^{\circ} \mathrm{C}$ for 30 days & $31668000 \pm 853542$ & $31174000 \pm 799235$ & 98.4 \\
\hline & IS $\left(500 \mathrm{ng} \mathrm{mL}^{-1}\right)$ & $25^{\circ} \mathrm{C}$ for 6 hours & $2958500 \pm 92984$ & $2975100 \pm 128621$ & 100.6 \\
\hline & & $0{ }^{\circ} \mathrm{C}$ for 6 hours & $3077500 \pm 103641$ & $2944500 \pm 96614$ & 95.7 \\
\hline & & $4{ }^{\circ} \mathrm{C}$ for 30 days & $2850300 \pm 86554$ & $2911700 \pm 100528$ & 102.1 \\
\hline \multirow[t]{2}{*}{ Stock solution } & $\mathrm{SP}\left(1 \mathrm{mg} \mathrm{mL}{ }^{-1}\right)$ & $-70^{\circ} \mathrm{C}$ for 90 days & $143 \pm 1.12$ & $145 \pm 0.976$ & 101.4 \\
\hline & IS $\left(1 \mathrm{mg} \mathrm{mL}^{-1}\right)$ & $-70^{\circ} \mathrm{C}$ for 90 days & $129 \pm 0.991$ & $127 \pm 0.852$ & 98.4 \\
\hline
\end{tabular}

${ }^{a}$ The $6 \mathrm{~h}$ stability at $25{ }^{\circ} \mathrm{C}$ and $0{ }^{\circ} \mathrm{C}$ was determined by comparing the peak area of the solutions before and after incubation. 
time points as in the previous section after incubation were collected to determine the concentrations of SP, and the halflives were calculated.

Acidified samples. The stability of the samples pre-treated with $\mathrm{H}_{2} \mathrm{SO}_{4}(0.1-0.3 \%, \mathrm{v} / \mathrm{v})$ and $\mathrm{HClO}_{4}(0.1-0.3 \%$, v/v) were estimated at ambient temperature $\left(25^{\circ} \mathrm{C}\right)$ and in an ice-water bath $\left(0{ }^{\circ} \mathrm{C}\right)$, respectively. The samples acidified with different reagents before incubation and at the same time points as in the previous section after incubation were collected to detect the variation of SP, and the half-lives were calculated.

\section{System suitability tests}

System suitability tests were utilized to confirm that the performance of the UHPLC-MS/MS system was applicable for batches to be done. A separate medium concentration sample (5 $\mathrm{ng} \mathrm{mL}{ }^{-1}$ ) was analysed as a reference standard before each run. The resolution and reproducibility of the UHPLC-MS/MS system were regarded as acceptable if the relative standard deviations (RSD\%) of the retention time and peak area of analytes from six replicate injections was no more than $15 \%$.

\section{Validation of the UHPLC-MS/MS assay}

The UHPLC-MS/MS method validation was performed on the basis of the bioanalytical guideline documented by the US Food and Drug Administration (2018). ${ }^{22}$ The following parameters were evaluated: selectivity and specificity, linearity, sensitivity (lower limit of quantification, LLOQ), carryover, precision, accuracy, stability, dilution integrity, matrix effect and extraction recovery.

Selectivity and specificity. Selectivity is the ability to which the assay can determine a particular analyte in biological matrices without endogen interference from the matrices. Specificity is the extent of the assay to determine, positively, the target component in the presence of other expected analytes. The selectivity and specificity of the assay were assessed using acidified blank rat plasma from six rats. Also, five LLOQ samples (reference samples) and six blank samples (with or without IS) were analysed and the interference at the retention time of SP and C-11 was evaluated. The acceptance criteria was the peak areas being no more than $20 \%$ of the average for the reference samples for SP and no more than $5 \%$ for C- 11 .

Linearity and sensitivity. The linearity was investigated by analysing seven non-zero calibration samples ranging from 0.1$200 \mathrm{ng} \mathrm{mL}^{-1}$, along with a double blank sample (no analyte, no IS) and a blank sample (containing $500 \mathrm{ng} \mathrm{mL}^{-1}$ of IS). The calibration curves were prepared in duplicate in each batch. Also, the calibration curves were supplied using the SP to IS peak area ratios by weighted linear least-squares $\left(1 / x^{2}\right)$ regression. The double blank and blank samples were not considered to calculate the calibration parameters. The sensitivity was evaluated by analysing five LLOQ samples in three independent batches. The correlation coefficients $(r$ ) of the calibration curves should be greater than 0.99. At least three quarters of the backcalculated concentrations should be within $15 \%$ deviation from the theoretical concentrations ( $20 \%$ for LLOQ level), and a minimum of six non-zero calibration levels should meet the above criteria. The LLOQ samples from sensitivity validation were acceptable when the accuracy was within $20 \%$ of the nominal concentration and the precision was greater than $20 \%$. Besides, the signal-to-noise $(\mathrm{S} / \mathrm{N})$ ratios of the LLOQ samples should be greater than 5 .

Carryover. Carryover was evaluated by injecting double blank samples, following the upper limit of quantification (ULOQ) samples in three separate batches during the method validation. The acceptance criterion was the peak areas being no more than $20 \%$ of the average of LLOQ samples for SP and no more than $5 \%$ for $\mathrm{C}-11$.

Precision and accuracy. The within-run and between-run precision and accuracy were performed by analysing the QC samples at three concentration levels and LLOQ samples in five replicates in three continuous validation runs over at least 2 days. The within-run and between-run precision was acceptable, if the RSD\% was no more than $15 \%$ for the QC samples and $20 \%$ for the LLOQ samples. The within-run and betweenrun accuracy was acceptable if the calculated concentrations were within $15 \%$ deviation from the theoretical concentrations for the QC samples and $20 \%$ for the LLOQ samples.

Stability. Stability studies were determined in the given matrix, including the effects of sample collection, processing and storage. The stability tests were assessed at low and high concentration levels $\left(0.25\right.$ and $\left.150 \mathrm{ng} \mathrm{mL}^{-1}\right)$ with five replicates under the following conditions: acidified whole blood samples stored in an ice-bath $\left(0{ }^{\circ} \mathrm{C}\right)$ for $1 \mathrm{~h}$, plasma samples stored at ambient temperature $\left(25^{\circ} \mathrm{C}\right)$ for $1 \mathrm{~h}$ before processing, extracted samples at ambient temperature $\left(25^{\circ} \mathrm{C}\right)$ for $1 \mathrm{~h}$, reconstituted samples in the auto-sampler $\left(4{ }^{\circ} \mathrm{C}\right)$ for $24 \mathrm{~h}$, plasma samples stored in a freezer $\left(-70{ }^{\circ} \mathrm{C}\right)$ for 60 days and plasma samples after three freeze-thaw (from $-70{ }^{\circ} \mathrm{C}$ to ambient temperature) cycles. In addition, the investigation of the stock solutions and working solutions stability was as described in the previous section. The accuracy (deviation from nominal concentration) at each level should be within $15 \%$.

Dilution integrity. The dilution integrity was evaluated by determining five replicates of QC samples at a concentration

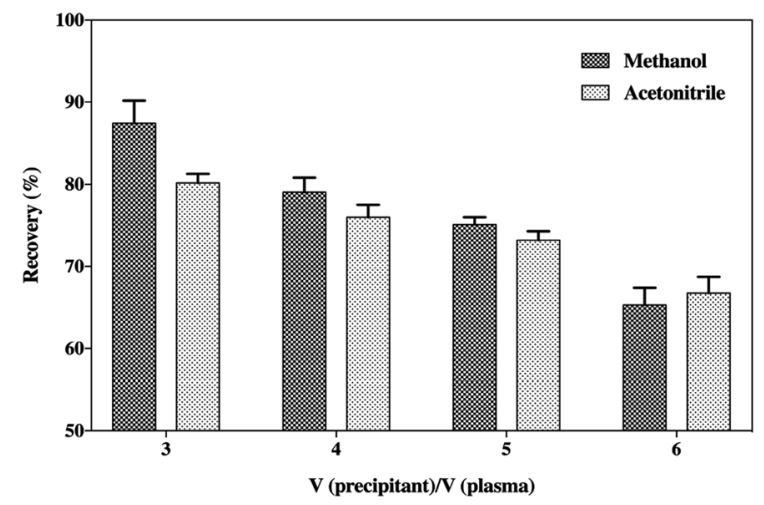

Fig. 4 Recovery of SP after plasma precipitation $(n=3)$. Blank acid rat plasma was spiked with SP $\left(5 \mathrm{ng} \mathrm{mL}^{-1}\right)$ and precipitated with methanol or acetonitrile containing $0.2 \%$ acetic acid $(\mathrm{v} / \mathrm{v})$ at the ratios indicated. $\mathrm{SP}$ in the supernatant was determined by UHPLC-MS/MS analysis and the recovery was calculated by comparing the peak areas of SP. 
level of $400 \mathrm{ng} \mathrm{mL} \mathrm{mL}^{-1}$ (two times the ULOQ) diluted with blank acidified rat plasma with a factor of 5. Also, the dilution factor was applicable if the accuracy (deviation from nominal concentration) was within $15 \%$ and the precision was better than $15 \%$.

Extraction recovery. The extraction recovery of the assay was investigated by comparing each SP to the IS peak area ratio at low, medium and high concentration levels (six replicates) with the mean ratio from the extracts of the blank samples spiked with the analyte post-extraction. The extraction recovery need not be $100 \%$, but the recovery of analytes should be reproducible and consistent. The extraction recovery was deemed acceptable if the RSD\% was no more than $15 \%$.

Matrix effect. The matrix effect of the assay was assessed at low and high concentration levels $(n=6)$ from six different rat plasma lots. Also, the matrix factors were determined by comparing the peak areas of the analytes spiked into postextracted blank plasma samples with the mean value from pure authentic standards at the same concentration levels. The matrix effect was deemed acceptable if the precision for the ISnormalised matrix factors was better than $15 \%$.

\section{Acceptable runs}

The calibration curve for each analytical batch should meet the acceptance criteria for linearity described in the previous section. Also, samples with at least three QC concentration levels $(n \geq 2)$ were tested in each analytical batch. In addition, the data from batches were qualified when at least two-thirds of the QC samples and at least half of the QC samples per level were within $15 \%$ deviation from the theoretical concentrations.
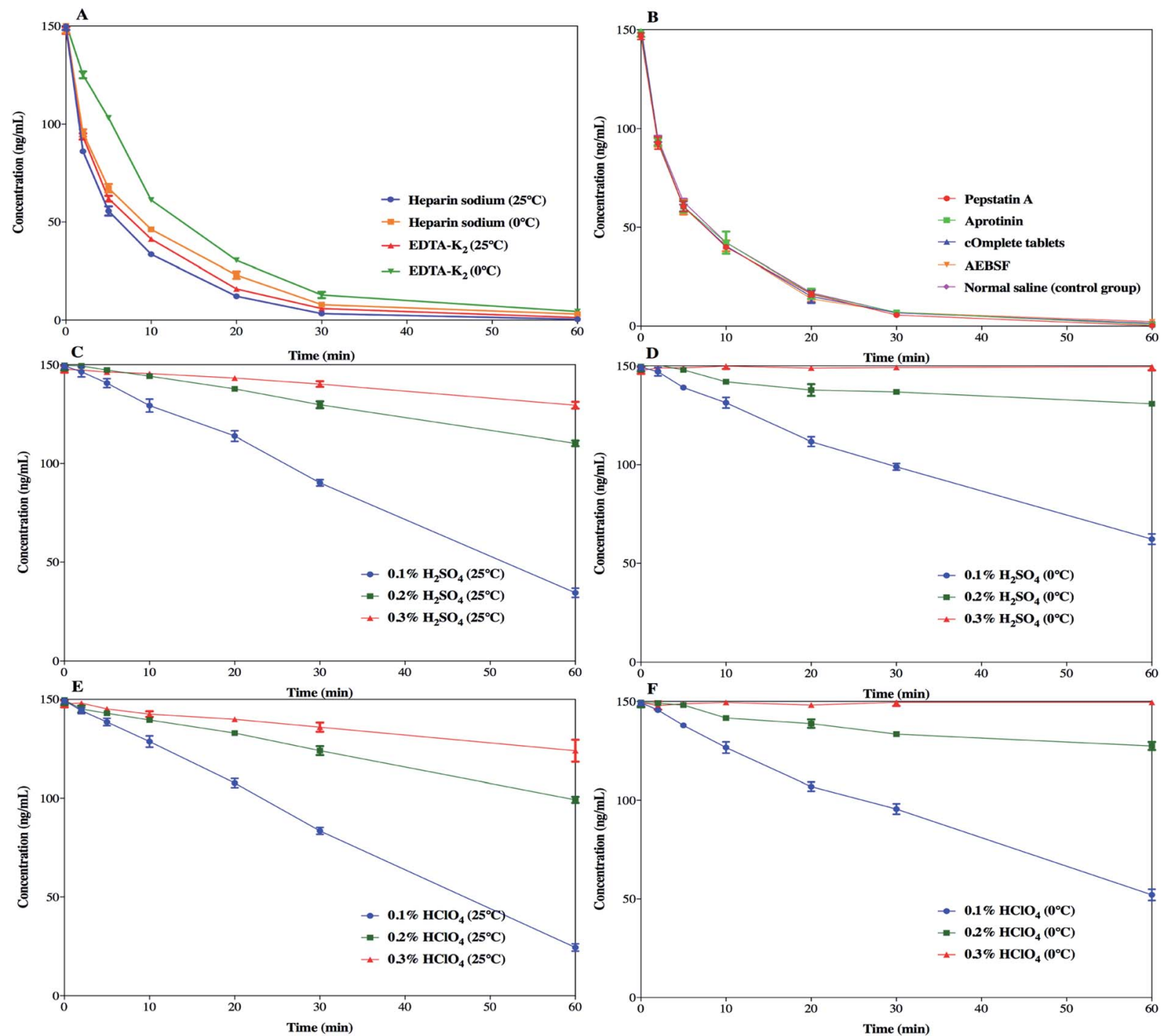

Fig. 5 Stability results of SP in blood samples under different test conditions $(n=3)$. (a) Blood samples using different anticoagulants at different temperatures; (b) blood samples inhibited by different enzyme inhibitors, including pepstatin A, aprotinin, cOmplete ${ }^{\mathrm{TM}}$ protease inhibitor cocktail tablets (cOmplete ${ }^{\mathrm{TM}}$ tablets) and AEBSF; (c) blood samples pre-treated with $\mathrm{H}_{2} \mathrm{SO}_{4}(0.1-0.3 \%, \mathrm{v}: \mathrm{v}$ ) at ambient temperature; (d) blood samples pre-treated with $\mathrm{H}_{2} \mathrm{SO}_{4}(0.1-0.3 \%, \mathrm{v}: \mathrm{v})$ in an ice-water bath; (e) blood samples pre-treated with $\mathrm{HClO}_{4}(0.1-0.3 \%$, v : v) at ambient temperature; (f) blood samples pre-treated with $\mathrm{HClO}_{4}(0.1-0.3 \%, \mathrm{v}: \mathrm{v})$ in an ice-water bath. 
Also, the acceptance criterion for the analytical batch containing the diluted samples was the same as above.

\section{Pharmacokinetic study}

Twelve Sprague-Dawley rats (female and male in half, $200 \pm 20 \mathrm{~g}$ for each) were purchased from Shanghai Slac Laboratory Animal Co., Ltd. (Shanghai, China). The rats were maintained under specific pathogen-free conditions with $12 \mathrm{~h}$ light-dark cycles, kept at $22 \pm 2{ }^{\circ} \mathrm{C}$ and a relative humidity of $55 \pm 15 \%$. The rats took commercial food and autoclaved water freely and adjusted themselves to their new situation for a week before experiment. The experimental workings were authorized by the Experimental Animal Care and Use Committee of SIPI, and appropriate animal welfare was seriously applied according to the related guidelines.

The rats were forced to stop food ingestion for about $12 \mathrm{~h}$ before receiving SP via subcutaneous administration $(10 \mathrm{mg}$ $\mathrm{kg}^{-1}$ ). The blood samples were collected via orbital bleeding into pre-acidified EDTA- $\mathrm{K}_{2}$ tubes at 0 (before administration), $0.5,1,2,3,5,10,20,30,45$ and $60 \mathrm{~min}$, following administration and placed in an ice-water bath $\left(0{ }^{\circ} \mathrm{C}\right)$ immediately. Then, the plasma samples were obtained by centrifugation at $1000 \times g$ for $15 \mathrm{~min}$ and stored at $-70{ }^{\circ} \mathrm{C}$ until analysis.

\section{Data treatment}

The data was acquired using the Analyst ${ }^{\circledR}$ software (Version 1.7, AB SCIEX), and data processing was performed using the MultiQuant $^{\mathrm{TM}}$ software (Version 3.0.3, AB SCIEX). During data analysis, the concentrations before administration below the LLOQ were defined as zero, and the concentrations after administration below LLOQ were defined as below LLOQ. The $T$ test results were evaluated with Microsoft ${ }^{\circledR}$ Excel for Mac 2011 (Microsoft Corp., USA). PK parameters were calculated using the Phoenix WinNonlin software (Version 6.3, Pharsight).

\section{Results and discussion}

\section{Method development}

In the present study context, a reliable and sensitive UHPLCMS/MS assay was developed for the determination of SP in rat plasma, and a stable cyclic peptide (C-11) acted as IS to improve the variability during bio-analysis.

Design of the IS for SP. The IS is a test compound added to both samples and calibration standards at constant concentrations to promote the quantification of the analyte. The IS should behave similar to the target peptide during sample preparation, chromatography and MS detection. Although the isotope-labelled peptide containing stable ${ }^{2} \mathrm{H}$ or ${ }^{13} \mathrm{C}$ isotope might act as a proper IS, its synthesis could be extremely expensive. The employment of structurally related analogues derived from an earlier structure-activity relationship examination during pharmaceutical development is usually supported. ${ }^{23}$ Also, alternatives to analogues obtained from amino acid exchange and other modifications of the peptide have been covered. $^{24,25}$ Furthermore, because such ISs and their correspondence to analytes are different in terms of molecular weight, separation and quantification can be easily performed without intricate processing. In the present study, a cyclic peptide (C-11) with a modified amino acid composition was synthesized and used as the IS for SP. Most notably, the half-life of $\mathrm{C}-11$ was longer than $60 \mathrm{~min}\left(25^{\circ} \mathrm{C}\right.$, in vitro $)$ compared to that of SP, which might result from some change in the metabolic sites.

Optimization of the mass conditions. The standard solutions (200 $\mathrm{ng} \mathrm{mL} \mathrm{mL}^{-1}$ ) of analytes were directly infused into the mass spectrometer with ESI or atmosphere pressure chemical

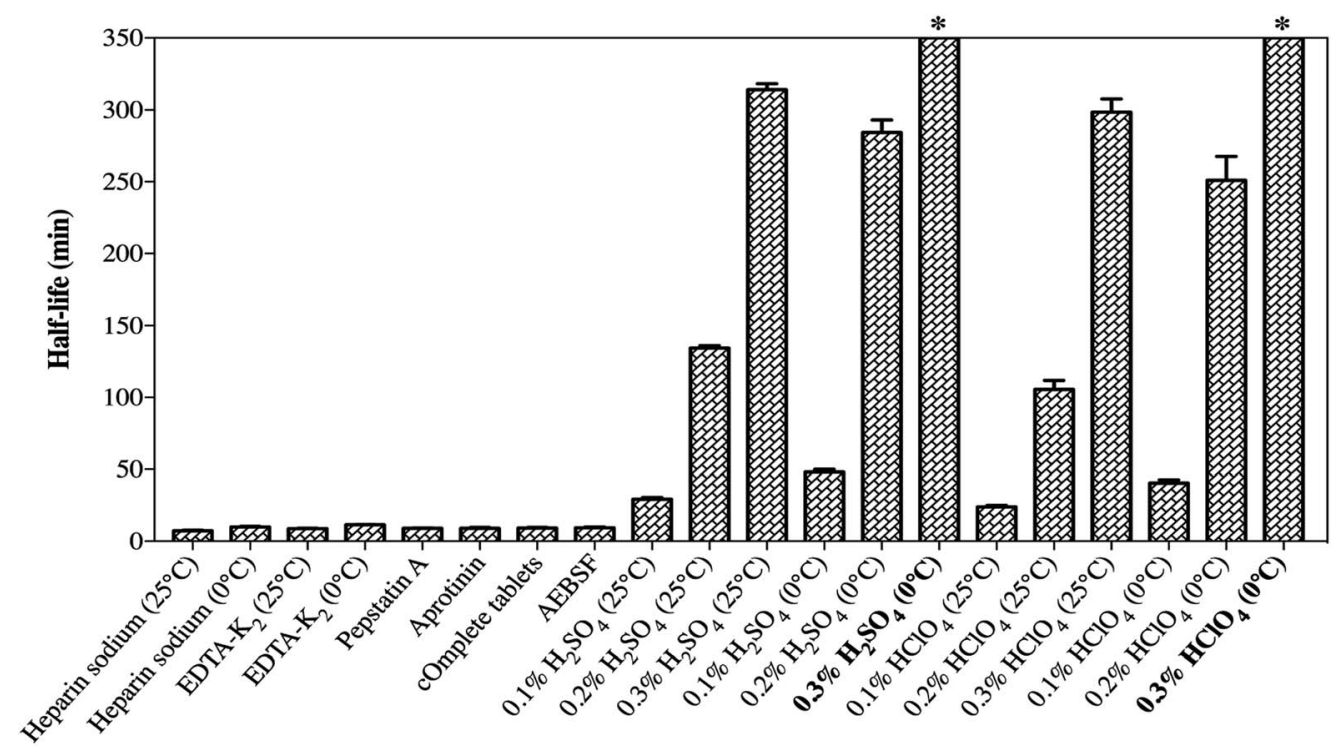

Fig. 6 Half-lives of SP in blood samples under different test conditions $(n=3)$. $* \mathrm{SP}$ in the blood samples acidified with $0.3 \% \mathrm{H}_{2} \mathrm{SO} \mathrm{O}_{4}(\mathrm{v}: \mathrm{v})\left(0{ }^{\circ} \mathrm{C}\right)$ and $0.3 \% \mathrm{HClO}_{4}(\mathrm{v}: \mathrm{v})\left(0^{\circ} \mathrm{C}\right)$ was highly stable, and the half-lives could not be calculated (that is, much more than $\left.350 \mathrm{~min}\right)$. 
ionization by a built-in syringe pump at a flow rate of 10 $\mu \mathrm{L} \min ^{-1}$. Also, the positive or negative ionization modes were evaluated to gain better ionization efficiency. The optimal signal stability and intensity was achieved in the ESI (+) analysis according to a observed full-scan mass spectrum. The MRM mode was employed to guarantee the specificity of the assay. In order to obtain the higher intensity at the LLOQ level, Q1 resolution was set at low. On the Q1 mass spectrum of SP and C11 , the predominant molecular ions $[\mathrm{M}+\mathrm{H}]^{+}$appeared at massto-charge ratios $(\mathrm{m} / \mathrm{z})$ of 713.3 and 803.2 and were selected as the precursor ions to obtain the product ions (Fig. 2). For the further investigation of the fragment ions of SP and C-11, the collision energy was regulated and a full-scan of the product ion was performed. The product ion mass spectrum of SP displayed the formation of abundant product ions at $\mathrm{m} / \mathrm{z} 638.3,551.1$, 432.3, 287.3 and 185.9 (Fig. 2a). On the product ion mass spectrum of $\mathrm{C}-11$, the characteristic fragment ions were recorded at $m / z$ 684.2, 539.3 and 438.1 (Fig. 2b). Due to the excellent charge stabilization of the conjugated $\pi$ electron systems, the most consistent product ions were the fragments from aromatic amino acids, which could produce a superior signal. ${ }^{26}$ Also, in consideration of the sensitivity and interference, molecular ion transitions at $m / z 713.3 \rightarrow 432.2$ for SP and $m / z 803.2 \rightarrow 539.1$ for IS were selected for the UHPLC-MS/MS analysis. Moreover, other mass spectrometry parameters were optimized to obtain the first-rank signal.

Optimization of the chromatographic conditions. Obtaining a good chromatographic performance for a linear heptapeptide with high polarity in the presence of certain complicatedly interferential substances from plasma was quite tough. First of all, different chromatographic columns, including a Waters ACQUITY UPLC® BEH C18 column $(2.1 \times 100 \mathrm{~mm}, 1.7 \mu \mathrm{m})$, Waters ACQUITY UPLC® HSS T3 column $(2.1 \times 50 \mathrm{~mm}, 1.8$ $\mu \mathrm{m})$, Waters ACQUITY UPLC® HILIC column $(2.1 \times 100 \mathrm{~mm}$, $1.7 \mu \mathrm{m})$ and Kromasil ${ }^{\circledR} \mathrm{C} 18$ column $(2.1 \times 100 \mathrm{~mm}, 4.6 \mu \mathrm{m})$ were evaluated to obtain the good peak shape and intensity. Also, the use of a SHIM-PACK GISS C18 column $(2.1 \times 100 \mathrm{~mm}$, $1.9 \mu \mathrm{m}$ ) maintained at $50{ }^{\circ} \mathrm{C}$ allowed for symmetrical peak
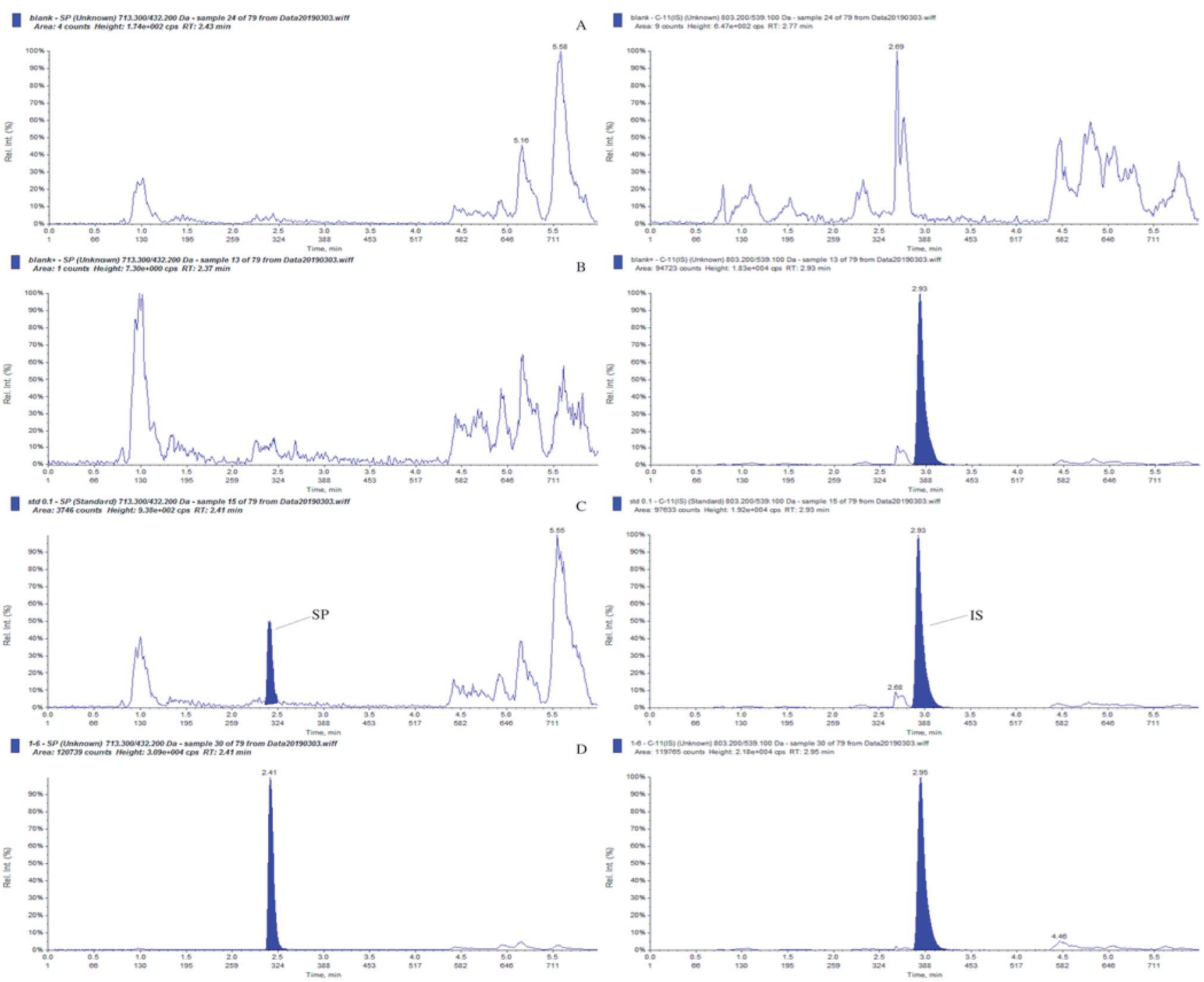

Fig. 7 Typical MRM chromatograms of SP and IS from (a) a double blank sample (no SP and IS); (b) blank sample (IS only); (c) LLOQ sample (0.1 ng $\left.\mathrm{mL}^{-1}\right)$; (d) sample taken at 10 min after administration $\left(20.3 \mathrm{ng} \mathrm{mL} \mathrm{L}^{-1}\right.$ ). 
shapes and satisfactory retention of the analytes. Besides, several attempts to optimize the composition of the mobile phase, including $0.1-0.4 \%$ acetic acid (v/v), $0.1-0.2 \%$ formic acid (v/v), 2-10 $\mathrm{mM}$ ammonium formate/acetate, acetonitrile and methanol, were conducted to achieve better peak shapes and a better response for the analytes. The results illustrated that methanol afforded a higher response for SP than acetonitrile. An aqueous phase containing $0.2 \%$ acetic acid (v/v) was found to provide a stronger signal intensity for SP than that containing $0.1-0.2 \%$ formic acid $(\mathrm{v} / \mathrm{v})$, which might result from the ionization efficiency. However, the aqueous phase containing more acetic acid could not exhibit an enhanced signal intensity. Therefore, methanol and water containing $0.2 \%$ acetic acid $(\mathrm{v} / \mathrm{v})$ were finally selected as the organic phase and aqueous phase for the UHPLC-MS/MS analysis due to their better performance in separation and greater ability to enhance the signal response. The programme was held for half a minute for a high proportion of the aqueous phase before the gradient to eliminate distractions from compounds with a higher polarity eluted at the same time as the targeted peptide. However, this failed to achieve the results hoped for and the plot was compromised with endogenous interference from the plasma samples in spite of several attempts to shorten the run time. Also, double gradient elution was addressed to solve this problem. The entire method validation and the PK study consisted of a huge number of samples. This UHPLC-MS/MS assay proved to offer wonderful repeatability for the chromatographic separation, and no significant variability of the retention times was detected after 150 injections. SP and IS were eluted at the retention times of $2.41 \pm 0.02 \mathrm{~min}$ and $2.95 \pm 0.01$ min under the optimized gradient condition $(\mathrm{RSD} \%=0.8 \%$ and $0.7 \%, n=$ 50). The total run time was $6 \mathrm{~min}$ for each sample.

\section{Estimation of the adsorption}

One of the most common traps run into during the inchoate development of analysis methods for peptides is the adsorption to the frequently used materials in instrumental analysis. A large number of factors could affect the detected concentrations of target peptides and the robustness of analysis methods, including, but not limited to, extraction recovery and matrix effects. The first thought concerns the nonspecific binding of target peptides to the solid surfaces of the containers. ${ }^{27}$ In addition, because the capacity of binding to the wall is limited, the relative loss caused by adsorption in low concentration solutions is more widespread than for high concentration samples. ${ }^{28}$ In the present study, a fast method composed of six consecutive steps for transferring the SP solutions (1 and 2000 $\mathrm{ng} \mathrm{mL}^{-1}$ ) and IS solution (500 $\mathrm{ng} \mathrm{mL}^{-1}$ ) from a container to another, followed by UHPLC-MS/MS analysis was developed. Also, a process for the experimental capacity measurement of the extent of adsorption was developed. The adsorption results of SP and IS are depicted in Fig. 3. No remarkable adsorption for SP and IS was observed for the test concentrations and three kinds of containers. Due to the hard-to-predict nature of the adsorption behaviour caused by the huge variability of amino acid sequences in peptides and their structural modifications, the adsorption aspect must be considered during quantitative analysis.

\section{Stock solutions and working solutions stability}

Considering the cysteine residue in C-11 is potentially sensitive to oxidation and the disulphide bond could be cleaved, leading to the amide bonds breaking down and releasing smaller fragments, stability tests for IS were necessary. The stabilities of the SP and IS in stock solutions and working solutions are shown in Table 2. The results demonstrated that there was no obvious degradation in the working solutions within the test concentrations after $6 \mathrm{~h}$ incubation at $25^{\circ} \mathrm{C}$ and $0{ }^{\circ} \mathrm{C}$, respectively. As shown in Table 2 , the working solutions of SP and IS were stable after being stored in an ice chamber $\left(4{ }^{\circ} \mathrm{C}\right)$ for 30 days, and the stock solutions of SP and IS were also stable after being stored in a freezer $\left(-70^{\circ} \mathrm{C}\right)$ for 90 days. Consequently, the two peptides were confirmed to have sufficient chemical stability during the process required for the UHPLC-MS/MS analysis.

\section{Precipitant selection}

The precipitation of the plasma samples with organic solvents could result in the removal of large abundant proteins, such as albumin, leaving only the low molecular weight proteins or peptides in solution. Moreover, the addition of ion-pairing agents, such as certain organic acids, could also separate the smaller proteins and peptides from the high molecular weight proteins, which is beneficial for the extraction of peptides. ${ }^{29}$ Also, the organic solvents should be kept below $4{ }^{\circ} \mathrm{C}$ to reduce thermally stressing the peptide. ${ }^{30}$ The precipitation of plasma samples was performed by spiking the samples with increasing the volumes of cooled acetonitrile or methanol with $0.2 \%$ acetic acid (v/v) to affect the deproteinization (Fig. 4). The results

Table 3 Precision and accuracy of SP in rat plasma samples

\begin{tabular}{|c|c|c|c|c|c|c|}
\hline \multirow[t]{2}{*}{ Within-run $(n=5)$} & Mean \pm SD & $0.109 \pm 0.003$ & $0.263 \pm 0.006$ & $4.95 \pm 0.352$ & $146 \pm 2.98$ & $387 \pm 11.4$ \\
\hline & Accuracy (\%) & 109.0 & 105.3 & 99.1 & 97.0 & 96.8 \\
\hline \multirow[t]{2}{*}{ Between-run $(n=15)$} & Mean $\pm \mathrm{SD}$ & $0.112 \pm 0.005$ & $0.269 \pm 0.016$ & $5.27 \pm 0.487$ & $142 \pm 3.73$ & - \\
\hline & Precision (RSD\%) & 4.5 & 5.9 & 9.2 & 2.6 & - \\
\hline
\end{tabular}


indicated that methanol was the best choice as the precipitant due to its more satisfactory recovery compared to acetonitrile. Although many papers have reported that the generic acetonitrile precipitation strategy is favourable for the extraction of small peptides in a biological matrix for mass spectrometry analysis, ${ }^{31-34}$ methanol was considered a better precipitating agent for SP in this study. Moreover, Fig. 4 also illustrates that the increase in the volumes of acetonitrile or methanol caused a tendency to reduce the recovery of SP. This suggests that increase in the volumes of organic solvents might cause a loss of the peptide to some extent on account of the co-precipitation or an insufficient solubility in a high concentration of precipitants. Solid-phase extraction (SPE) was frequently applied during the sample preparation process to avoid possible interferences that could impact the result of the UHPLC-MS/MS analysis, but it finally fell out of favour owing to its unsatisfactory accuracy and poor precision of the assay. Hence, the handy protein precipitation by applying triple volumes of cooled methanol containing $0.2 \%$ acetic acid $(\mathrm{v} / \mathrm{v})$ was applied to extract the peptide from the plasma samples.

\section{Stabilization of the SP in the samples}

SP was detected to have insufficient chemical stability in the samples as a result of enzymatic degradation. As it is wellknown, the preclinical samples collected from rats are in the form of whole blood, and stabilization should be considered in the sampling step. Therefore, different stabilization tactics for the blood samples were investigated so as to identify the degradation process and to determine the optimal sample processing method.

The effects of different anticoagulants on the stability of SP in the samples are shown in Fig. 5a. EDTA-K2 was used as an anticoagulant and the samples were kept at $0{ }^{\circ} \mathrm{C}$, which simultaneously slightly improved the degradation of SP, which prolonged the half-life to $11.48 \pm 0.22 \mathrm{~min}$. This suggested that EDTA-K2 could be a better choice for its potential inhibition of metal-catalysed oxidation, but it could not meet all our needs. The addition of protease inhibitors, such as pepstatin A, aprotinin, complete ${ }^{\mathrm{TM}}$ protease inhibitor cocktail tablets and AEBSF, did not slow down the degradation process compared to the control group (Fig. 5b). The results (Fig. 6) showed that there was no significant change in the half-life of SP. As illustrated in Fig. $5 \mathrm{c}$ and $\mathrm{d}$ and Fig. 5e and $\mathrm{f}$, the samples pre-treated with $0.3 \% \mathrm{H}_{2} \mathrm{SO}_{4}(\mathrm{v} / \mathrm{v})$ or $0.3 \%$ $\mathrm{HClO}_{4}(\mathrm{v} / \mathrm{v})$ combined with an ice-water bath were stable within $1 \mathrm{~h}$. Also, the half-life of SP in both the blood samples acidified with $0.3 \% \mathrm{H}_{2} \mathrm{SO}_{4}(\mathrm{v} / \mathrm{v})$ or $0.3 \% \mathrm{HClO}_{4}(\mathrm{v} / \mathrm{v})$ was far longer than $350 \mathrm{~min}$ (Fig. 6). This suggested that the pretreatment with acidification agents could significantly improve the degradation and afford a fairly stable environment for SP. However, we found that the samples acidified with $0.3 \% \mathrm{H}_{2} \mathrm{SO}_{4}(\mathrm{v} / \mathrm{v})$ produced extra signal suppression and impacted the sensitivity during UHPLC-MS/MS analysis. We also speculated that the samples were moderately haemolysed, which might have resulted in severe matrix effects. Accordingly, the addition of $0.3 \% \mathrm{HClO}_{4}(\mathrm{v} / \mathrm{v})$ into the samples was finally applied to stabilize SP.

The enzymatic degradation of SP in blood is a sophisticated process and the mechanism has not been fully probed fully before. The relevant protease inhibitors did not block the degradation of SP, manifesting that the corresponding protease hydrolysis might not be the critical mechanism behind the degradation. In addition, other kinds of enzymes may be conducive to the degradation. Hence, an extensive investigation of different stabilization factors was accomplished to elucidate the SP process. An effective, low-cost and time-saving stabilization tactic is presented in this study despite the mechanism of degradation still not being explicitly set out. Moreover, hydrochloric acid and formic acid were not adopted due to their volatility, which goes against the long-term stability (unpublished data). Moreover, phosphoric acid could bring about acute haemolysis and nearly curdle the blood samples, and was thus discarded. Finally, it was demonstrated that simply pretreating the samples with $0.3 \% \mathrm{HClO}_{4}(\mathrm{v} / \mathrm{v})$ combined with EDTA-K2 as an anticoagulant and sitting in an ice-water bath was suitable for inhibiting the activity of the enzymes and stabilizing SP.

Table 4 Stability results of SP under different conditions

\begin{tabular}{|c|c|c|c|c|c|}
\hline \multirow[t]{7}{*}{ Plasma } & Short-term stability $\left(0{ }^{\circ} \mathrm{C}\right.$ for $\left.1 \mathrm{~h}\right)$ & 0.25 & $0.241 \pm 0.011$ & 4.6 & 96.4 \\
\hline & \multirow[t]{2}{*}{ Post-preparation stability $\left(25^{\circ} \mathrm{C}\right.$ for $\left.1 \mathrm{~h}\right)$} & 0.25 & $0.227 \pm 0.018$ & 7.9 & 90.8 \\
\hline & & 150 & $158 \pm 6.12$ & 3.9 & 105.3 \\
\hline & Auto-sampler stability $\left(4{ }^{\circ} \mathrm{C}\right.$ for $\left.24 \mathrm{~h}\right)$ & 0.25 & $0.275 \pm 0.009$ & 3.3 & 110.0 \\
\hline & Freeze-thaw stability (three cycles) & 150 & $142 \pm 4.21$ & 3.0 & 94.7 \\
\hline & \multirow[t]{2}{*}{ Long-term stability $\left(-70^{\circ} \mathrm{C}\right.$ for 60 days $)$} & 0.25 & $0.240 \pm 0.005$ & 2.1 & 96.1 \\
\hline & & 150 & $141 \pm 3.85$ & 2.7 & 94.0 \\
\hline \multirow[t]{2}{*}{ Blood } & \multirow[t]{2}{*}{ Blood stability $\left(0{ }^{\circ} \mathrm{C}\right.$ for $\left.1 \mathrm{~h}\right)$} & 0.5 & $0.572 \pm 0.078$ & 13.6 & 114.4 \\
\hline & & 300 & $312 \pm 10.0$ & 3.2 & 104.1 \\
\hline
\end{tabular}




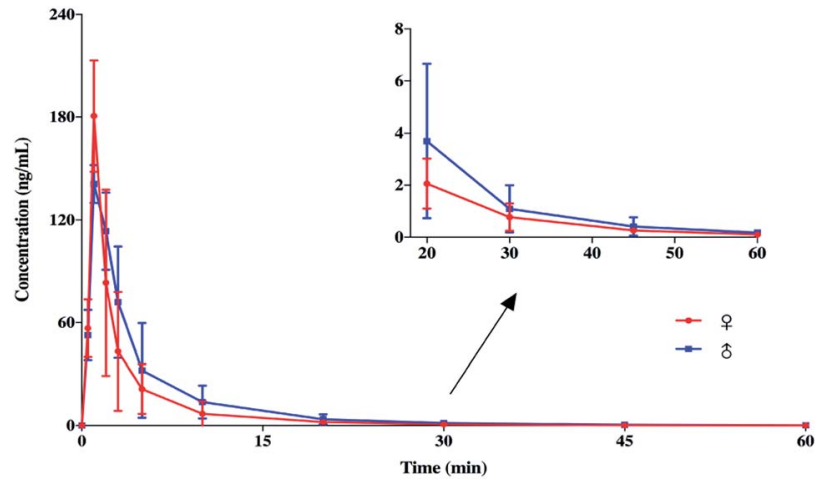

Fig. 8 Mean plasma concentration-time profiles of female and male Sprague-Dawley rats after a subcutaneous administration of $10 \mathrm{mg}$ $\mathrm{kg}^{-1}(n=6)$.

\section{Method validation}

Selectivity and specificity. The selectivity and specificity were evaluated by comparing acidified blank plasma samples from six matrices with the spiked samples. The representative UHPLC-MS/MS chromatograms are illustrated in Fig. 7. Fig. 7a shows there was no obvious interference from endogenous compounds in the blank rat plasma at the retention times of SP and $\mathrm{C}-11$. As depicted in Fig. 7b, the absence of C-11 did not exert direct interference on the MRM channel of SP. Fig. 7c shows a typical chromatogram for the LLOQ sample. It was indicated that all the plasma lots were free of interference from the analytes.

Linearity and sensitivity. The resulting standard calibration curves for SP from three independent batches demonstrated that good linearity was obtained in the range of $0.1-200 \mathrm{ng}$ $\mathrm{mL}^{-1}$ in rat plasma by using a weighting factor of $1 / x^{2}$. Also, the correlation coefficient of each standard calibration curve was greater than 0.9977 . The RSD\% values for each point of the standard calibration curves were all below $8.7 \%$, and the accuracies of the back-calculated concentrations ranged from $93.1 \%$ to $106.8 \%$. For sensitivity, Table 3 shows that the acceptable accuracy (within $\pm 12.0 \%$ ) and precision (RSD\% $<2.8 \%$ ) for LLOQ samples were performed with $\mathrm{S} / \mathrm{N}$ ratios above 5 . The assay for the quantitation of SP could afford an LLOQ of $0.1 \mathrm{ng}$ $\mathrm{mL}^{-1}$ with $50 \mu \mathrm{L}$ of rat plasma.

Carryover. Carryover for the analyte and IS, expressed as the percentage of the LLOQ samples, was less than $7.4 \%$ and $0.7 \%$, respectively. It was suggested that no direct interference of the analytes from a preceding sample was observed.

Precision and accuracy. LLOQ samples and QC samples were analysed to identify the precision and accuracy of the assay, and the results are summarized in Table 3. The within-run and between-run precisions were less than $7.1 \%$ and $9.2 \%$, respectively. Also, the within-run and between-run accuracies were within $96.8-109.0 \%$ and $94.7-112.0 \%$, respectively, compared to the theoretical concentrations. The data demonstrated that the present method was robust and reproducible with excellent accuracy and precision.
Stability. The results of the stability studies are shown in Table 4. Regarding the short-term stability, acidified blood samples were stable at $0{ }^{\circ} \mathrm{C}$ for $1 \mathrm{~h}$, and unprocessed plasma samples were also stable at room temperature after being incubated for $1 \mathrm{~h}$. Regarding the post-preparation stability, the extracted samples remained stable at room temperature for $1 \mathrm{~h}$. As depicted in Table 4, the re-dissolved samples were deemed as stable when kept in the auto-sampler at $4{ }^{\circ} \mathrm{C}$ for $24 \mathrm{~h}$. The stability of freeze-thaw proved that SP was stable in acidified rat plasma while stored at $-70{ }^{\circ} \mathrm{C}$ and then thawed to ambient temperature for three cycles. In terms of the long-term stability, the data indicated a reliable stability for SP during 60 days storage at $-70{ }^{\circ} \mathrm{C}$ in acidified rat plasma.

Dilution integrity. The dilution samples prepared at two times the ULOQ were diluted fivefold, along with QC samples and a standard calibration curve was plotted, and the results are shown in Table 3. It was revealed that the precision of the diluted samples was lower than $2.9 \%$ and the accuracy was greater than $96.8 \%$, which met the acceptance criteria. Hence, dilution with a factor of 5 was qualified for the determination of SP.

Extraction recovery. Protein precipitation was used for extracting the analytes from the acidified plasma samples, affording united extraction efficiencies for SP and C-11. The average extraction recoveries of SP from rat plasma at three concentrations levels ranged from $82.7 \%$ to $86.9 \%$, together with acceptable precisions (RSD\% $\leq 3.5 \%)$. Also, the IS had a similar recovery $(84.4 \pm 3.02 \%)$ compared to the corresponding analyte. This suggested that the IS, C-11, was adequate for facilitating the quantification of SP during the UHPLC-MS/MS analysis.

Matrix effect. The average IS-normalized matrix factors for $\mathrm{SP}$ at concentrations of $0.25 \mathrm{ng} \mathrm{mL} \mathrm{m}^{-1}$ and $150 \mathrm{ng} \mathrm{mL} \mathrm{m}^{-1}$ were $97.8 \pm 3.6 \%$ and $99.3 \pm 7.2 \%$. Also, the precisions were within acceptable limits $(\mathrm{RSD} \% \leq 3.7 \%)$. These results convincingly proved that no susceptible signal suppression or enhancement was detected and the matrix effect was negligible.

\section{Application to pharmacokinetic study}

The fully validated UHPLC-MS/MS method was applied to a PK study of SP. Single-dose data in 12 Sprague-Dawley rats (equal number females and males) weighing $200 \pm 20 \mathrm{~g}$ was obtained after a subcutaneous dose of $10 \mathrm{mg} \mathrm{kg}^{-1}$ was administered. The typical MRM chromatogram from a rat plasma sample taken at 10 min after administration is shown in Fig. $7 d$, and the concentration of SP was $20.3 \mathrm{ng} \mathrm{mL}^{-1}$. The mean plasma concentration-time profiles of the female and male SpragueDawley rats after a single subcutaneous administration are illustrated in Fig. 8. It was demonstrated that there was no significant statistical difference between the plasma concentrations of female rats and male rats $(p>0.5)$. Also, it was indicated that the PK behaviour in rats was independent of gender differences. Furthermore, an examination of Fig. 8 shows that the developed UHPLC-MS/MS method possessed 
Table 5 Main pharmacokinetic parameters of SP in rats after the subcutaneous administration of $10 \mathrm{mg} \mathrm{kg}^{-1 a}$

\begin{tabular}{lll}
\hline Parameters & Unit & $\begin{array}{l}\text { Values } \\
\text { (mean } \pm \mathrm{SD}, n=12)\end{array}$ \\
\hline $\mathrm{AUC}_{0-\mathrm{t}}$ & $\mathrm{ng} \mathrm{min} \mathrm{mL}$ & $712 \pm 43.0$ \\
$\mathrm{AUC}_{0-\infty}$ & $\mathrm{ng} \mathrm{min} \mathrm{mL}$ & $714 \pm 43.3$ \\
$C_{\max }$ & $\mathrm{ng} \mathrm{mL}$ & $210 \pm 21.6$ \\
$T_{\max }^{-1}$ & $\mathrm{~min}$ & $1.75 \pm 0.957$ \\
$T_{1 / 2}$ & $\mathrm{~min}$ & $8.65 \pm 1.79$ \\
$\mathrm{CL}$ & $\mathrm{L} \mathrm{min}$ & $17.9 \pm 9.96$ \\
$\mathrm{Vz}$ & $\mathrm{L}$ & $230 \pm 118$
\end{tabular}

${ }^{a} \mathrm{AUC}_{0-\mathrm{t}}$, area under the plasma concentration-time profile from 0 to $60 \mathrm{~min} ; \mathrm{AUC}_{0-\infty}$, area under the plasma concentration-time profile from 0 to infinity; $C_{\max }$, maximum concentration; $T_{\max }$, time to $C_{\max }$; $T_{1 / 2}$, elimination half-life; CL, apparent total plasma clearance; Vz, total volume of distribution.

the desired sensitivity to display the absorption, distribution and elimination process of SP following subcutaneous infusion.

The PK parameters were evaluated by using a noncompartmental model and the results are summarized in Table 5. After subcutaneous administration, the mean maximum concentration $\left(C_{\max }\right)$ of SP in plasma was $210 \pm 21.6$ $\mathrm{ng} \mathrm{mL}^{-1}$ and the area under the plasma concentration-time profile $\left(\mathrm{AUC}_{0-\mathrm{t}}\right)$ was $712 \pm 43.0 \mathrm{ng} \mathrm{min} \mathrm{mL}^{-1}$. The plasma concentration of SP declined by $50 \%$ within $10 \mathrm{~min}\left(T_{1 / 2}=8.65\right.$ $\pm 1.79 \mathrm{~min}$ ), and the LLOQ level of the assay was reached at around 60 min (Fig. 8). This indicates SP could be a therapeutic peptide candidate for inflammatory-related diseases, because the continuous existence of compounds in the body might cause adverse events related to immunomodulatory therapies. Fast absorption was found following the subcutaneous administration of $10 \mathrm{mg} \mathrm{kg}^{-1} \mathrm{SP}$ with the $T_{\max }$ at $1.75 \pm 0.957 \mathrm{~min}$.

\section{Conclusion}

In conclusion, a reliable, simple and sensitive UHPLC-MS/MS method with a stable cyclic peptide acting as an IS was successfully developed for the determination of SP in rat plasma and fully validated according to the latest bioanalytical guideline documented by the US Food and Drug Administration. Also, it fulfilled all the acceptance criteria for working as a bioanalytical method in pharmaceutical analysis. The instability of SP in blood samples, a primary challenge for the analysis, was cracked by acidifying the blood samples with perchloric acid $(0.3 \%, \mathrm{v} / \mathrm{v})$. Besides, a simple deproteinization was employed to extract the peptide from the plasma samples, which did not require a complicated pre-treatment, thus shortening the sample processing and weakening the variability of the assay. The expected sensitivity of SP was accomplished with an LLOQ of $0.1 \mathrm{ng} \mathrm{mL}^{-1}$ using $50 \mu \mathrm{L}$ of plasma. Also, clearly, the proposed UHPLC-MS/MS assay for the quantitation of SP could provide reference for the determination of other unstable small peptides in biological matrices. The application of the fully verified method to a PK study of SP in rats during preclinical stage enabled calculation of the main PK parameters. It was found that SP was eliminated quickly from body with a half-life of less than $10 \mathrm{~min}$, which was a promising result for an immunomodulatory candidate in the field of safety for the reason that some inflammatory-related diseases, such as asthma, would require repeated doses. The work could provide the basis for further in-depth studies into a clinical assay of SP.

\section{Conflicts of interest}

There are no conflicts to declare.

\section{Acknowledgements}

This work was funded by the Science and Technology Commission of Shanghai Municipality (No. 18DZ2290900). We greatly appreciate the sacrificial rats for their contribution to the study of SP in this work. And we also thank Jinqiu Mo for their help on the publication. Additionally, Liang Li wants to thank, in particular, the support and company from Yueying Zhi over the years.

\section{Notes and references}

1 Y. Wu, S. Antony, J. L. Meitzler and J. H. Doroshow, Cancer Lett., 2014, 345, 164-173.

2 S. La Manna, C. Di Natale, D. Florio and D. Marasco, Int. J. Mol. Sci., 2018, 19, 2714.

3 P. C. Calder, R. Albers, J. M. Antoine, S. Blum, R. BourdetSicard, G. A. Ferns, G. Folkerts, P. S. Friedmann, G. S. Frost, F. Guarner, M. Løvik, S. MacFarlane, P. D. Meyer, L. M'Rabet, M. Serafini, W. Van Eden, J. Van Loo, W. Vas Dias, S. Vidry, B. M. Winklhofer-Roob and J. Zhao, Br. J. Nutr., 2009, 101, S1-S45.

4 Q. Alam, M. Zubair Alam, G. Mushtaq, G. A. Damanhouri, M. Rasool, M. Amjad Kamal and A. Haque, Curr. Pharm. Des., 2016, 22, 541-548.

5 D. Okin and R. Medzhitov, Curr. Biol., 2012, 22, 733-740.

6 S. La Manna, P. L. Scognamiglio, C. Di Natale, M. Leone, F. A. Mercurio, A. M. Malfitano, F. Cianfarani, S. Madonna, S. Caravella, C. Albanesi, E. Novellino and D. Marasco, Biochimie, 2017, 138, 106-115.

7 J. L. Lau and M. K. Dunn, Bioorg. Med. Chem., 2018, 26, 27002707.

8 E. B. M. Daliri, B. H. Lee and D. H. Oh, Crit. Rev. Food Sci. Nutr., 2018, 58, 2273-2284.

9 Y. S. Chang, B. Graves, V. Guerlavais, C. Tovar, K. Packman, K.-H. To, K. A. Olson, K. Kesavan, P. Gangurde, A. Mukherjee, T. Baker, K. Darlak, C. Elkin, Z. Filipovic, F. Z. Qureshi, H. Cai, P. Berry, E. Feyfant, X. E. Shi, J. Horstick, D. A. Annis, A. M. Manning, N. Fotouhi, H. Nash, L. T. Vassilev and T. K. Sawyer, Proc. Natl. Acad. Sci. U. S. A., 2013, 110, E3445-E3454.

10 T. Uhlig, T. Kyprianou, F. G. Martinelli, C. A. Oppici, D. Heiligers, D. Hills, X. R. Calvo and P. Verhaert, EuPa Open Proteomics, 2014, 4, 58-69.

11 H. R. Hoogenboom, Nat. Biotechnol., 2005, 23, 1105-1116. 
12 C. H. Wu, Y. H. Kuo, R. L. Hong and H. C. Wu, Sci. Transl. Med., 2005, 7, 290-291.

13 X. Forns, R. H. Purcell and J. Bukh, Trends Microbiol., 1999, 7, 402-410.

14 L. Frasca, C. Scottà, P. Del Porto, A. Nicosia, C. Pasquazzi, I. Versace, A. M. Masci, L. Racioppi and E. Piccolella, Hepatology, 2003, 38, 653-663.

15 Y. K. Shimizu, H. Yoshikura, M. Shapiro, H. Igarashi, D. C. Wong, T. Kiyohara and R. H. Purcell, J. Gen. Virol., 2015, 79, 1383-1386.

16 R. Thimme, V. Lohmann and F. Weber, Antiviral Res., 2006, 69, 129-141.

17 J. L. Haibin Sun and S. Chi, J. Chin. PLA Postgrad. Med. Sch., 2006, 27, 254-256.

18 C. Song, L. Chen, B. Yang, S. Chi and Y. Cheng, J. Med. Coll. $P L A, 2010,25,257-266$.

19 W. Zhaob, L. Wanga, P. Chenc, J. Zhaoa, Y. Qia, S. Chia, J. Suna, L. Zhua and Y. Chenga, Inflammation Allergy: Drug Targets, 2010, 9, 135-145.

20 Y. C. Chuihui Song and B. Yang, Med. J. Chin. People's Liberation Army, 2009, 34, 1333-1334.

21 H. Jiang, J. Li, X. Zhao, Y. Zhou, Y. Li, F. Sun, X. Hu, J. Huang, Y. Rui and G. Fan, J. Pharm. Biomed. Anal., 2013, 83, 305-313.

22 U.S. Department of Health and Human Services, Food and Drug Administration, Guidance for Industry: Bioanalytical Method Validation, http://www.fda.gov/downloads/Drugs/ Guidances/ucm070107.pdf.

23 D. S. W. Palagama, D. Baliu-Rodriguez, A. Lad, B. S. Levison, D. J. Kennedy, S. T. Haller, J. Westrick, K. Hensley and D. Isailovic, J. Chromatogr. A, 2018, 1573, 66-77.
24 L. A. Dahabiyeh, D. Tooth, R. W. Carrell, R. J. Read, Y. Yan, F. B. Pipkin and D. A. Barrett, Anal. Bioanal. Chem., 2019, 411, 427-437.

25 H. Fouda, M. Nocerini, R. Schneider and C. Gedutis, J. Am. Soc. Mass Spectrom., 1991, 2, 164-167.

26 J. H. Gross, Mass Spectrometry, Springer-Verlag, Berlin, 1st edn, 2004.

27 A. Garcia-Ac, S. V. Duy, S. Sauvé, F. Moldovan, V. G. Roullin and X. Banquy, Talanta, 2018, 186, 124-132.

28 P. Hyenstrand, J. S. Metcalf, K. A. Beattie and G. A. Codd, Toxicon, 2001, 39, 589-594.

29 O. Chertov, A. Biragyn, L. W. Kwak, J. T. Simpson, T. Boronina, V. M. Hoang, D. R. A. Prieto, T. P. Conrads, T. D. Veenstra and R. J. Fisher, Proteomics, 2010, 4, 11951203.

30 M. Shimizu, P. Swanson, H. Fukada, A. Hara and W. W. Dickhoff, Gen. Comp. Endocrinol., 2000, 119, 26-36.

31 C. Polson, P. Sarkar, B. Incledon, V. Raguvaran and R. Grant, J. Chromatogr. B: Anal. Technol. Biomed. Life Sci., 2003, 785, 263-275.

32 J. Ma, J. Shi, H. Le, R. Cho, J. C. jou Huang, S. Miao and B. K. Wong, J. Chromatogr. B: Anal. Technol. Biomed. Life Sci., 2008, 862, 219-226.

33 R. S. Tirumalai, K. C. Chan, D. A. Prieto, H. J. Issaq, T. P. Conrads and T. D. Veenstra, Mol. Cell. Proteomics, 2003, 2, 1096-1103.

34 R. Kay, C. Barton, L. Ratcliffe, B. Matharoo-Ball, P. Brown, J. Roberts, P. Teale and C. Creaser, Rapid Commun. Mass Spectrom., 2008, 22, 3255-3260. 